\title{
Thin-Film ZnO Charge-Trapping Memory Cell Grown in a Single ALD Step
}

\author{
Feyza B. Oruç, Furkan Cimen, Ayman Rizk, Mohammad Ghaffari, Ammar Nayfeh, Member, IEEE, and \\ Ali K. Okyay, Member, IEEE
}

\begin{abstract}
A thin-film $\mathrm{ZnO}$-based single-transistor memory cell with a gate stack deposited in a single atomic layer deposition step is demonstrated. Thin-film $\mathrm{ZnO}$ is used as channel material and charge-trapping layer for the first time. The extracted mobility and subthreshold slope of the thin-film device are $23 \mathrm{~cm}^{2} / \mathrm{V} \cdot \mathrm{s}$ and $720 \mathrm{mV} / \mathrm{dec}$, respectively. The memory effect is verified by a 2.35-V hysteresis in the $I_{\text {drain }}-V_{\text {gate }}$ curve. Physics-based TCAD simulations show very good agreement with the experimental results providing insight to the charge-trapping physics.
\end{abstract}

Index Terms-Atomic layer deposition (ALD), Flash memory, thin-film transistor (TFT), ZnO.

\section{INTRODUCTION}

$\mathbf{M}$ ETAL-oxide semiconductors ( $\mathrm{ZnO}$ and IGZO) have been extensively investigated recently as channel materials for thin-film transistors (TFTs). For low-cost flexible electronics, low-temperature techniques are of critical importance. TFTs were demonstrated using $\mathrm{ZnO}$ channels deposited by sputtering [1]-[5], atomic layer deposition (ALD) [6]-[9], and pulsed laser deposition [10], [11]. For functional electronics, integrated sensors and data storage devices are also required on such a cost-effective platform. Flash memory devices with low-cost $\mathrm{ZnO}$ channel materials are demonstrated [12]-[15]. The ALD technique is promising due to low-temperature growth, large-area uniformity, precise thickness control, highly conformal deposition, and scalability to roll-to-roll processes. Memory devices using the ALD $\mathrm{ZnO}$ channel are recently demonstrated [15]; however, the gate stack and the trapping layer are grown by the plasma-enhanced CVD technique. In addition, there are earlier reports on the use of wide band-gap amorphous semiconductors [13] and semiconductor nanoparticle [16] layers as both channel and trap layers in memory devices. However, in these reports, amorphous GaInZnO layers are deposited by RF magnetron sputtering [13], and $\mathrm{ZnO}$

Manuscript received September 7, 2012; accepted September 14, 2012. Date of publication October 26, 2012; date of current version November 22, 2012. This work was supported in part by the European Union FP7 Marie Curie IRG under Grant 239444; by the COST NanoTP; and by the Scientific and Technological Research Council of Turkey (TÜBÝTAK) under Grant 108E163, Grant 109E044, Grant 112M004, and Grant 112E052. The review of this letter was arranged by Editor S. J. Koester.

F. B. Oruç, F. Cimen, M. Ghaffari, and A. K. Okyay are with the Department of Electrical and Electronics Engineering and UNAM-Institute of Materials Science and Nanotechnology, Bilkent University, Ankara 06800, Turkey (e-mail: aokyay@ee.bilkent.edu.tr).

A. Rizk and A. Nayfeh are with Masdar Institute of Science and Technology, Abu Dhabi, United Arab Emirates.

Color versions of one or more of the figures in this letter are available online at http://ieeexplore.iee.org.

Digital Object Identifier 10.1109/LED.2012.2219493

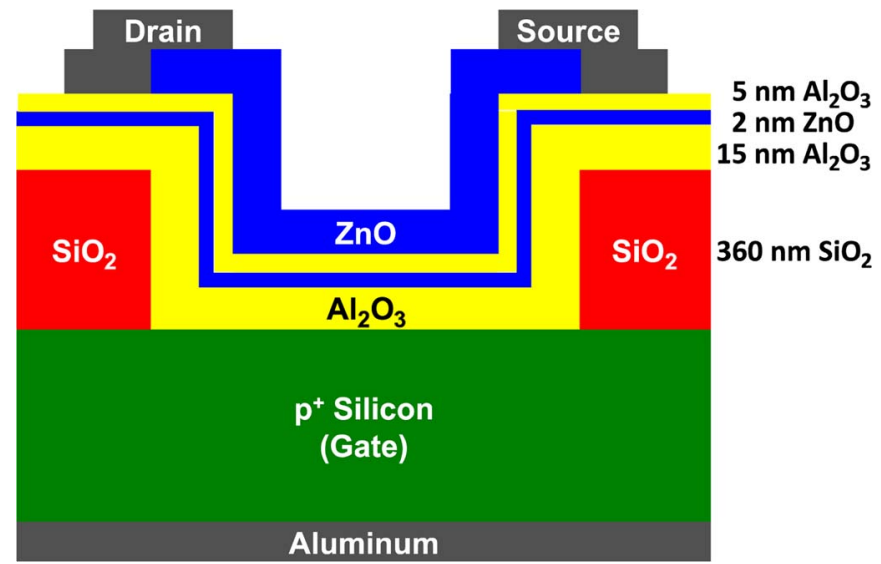

Fig. 1. Schematic of the thin-film all-ALD memory cell.

nanoparticles are coated by solution processing [16]; whereas other techniques are used to deposit dielectric layers. An ALD approach offers a simplified high-throughput single-step approach to obtain very high-quality complete gate stacks. Such an approach avoids risk of contamination or incorporation of impurities in the gate stack, increase the throughput significantly by eliminating multiple equipment utilization for the gate stack, and therefore offer a novel path for ultralow-cost integrated devices.

In this letter, we demonstrate a memory device with a gate stack fabricated in a single ALD step. Wide band-gap $\mathrm{ZnO}$ is used as the charge trapping and channel layer for concept demonstration. Fig. 1 depicts the structure of an all-ALD memory cell illustrating the ALD-deposited gate stack, including the transistor channel $(\mathrm{ZnO})$, tunnel oxide $\left(\mathrm{Al}_{2} \mathrm{O}_{3}\right)$, chargetrapping layer $(\mathrm{ZnO})$, and charge blocking layer $\left(\mathrm{Al}_{2} \mathrm{O}_{3}\right)$. In addition, physics-based TCAD simulations are compared with experimental results providing further insight into the chargetrapping mechanism.

\section{DEVICE FABRICATION AND CHARACTERIZATION}

\section{A. Fabrication}

Channel-last all-ALD memory devices are fabricated on a highly doped $(10-18 \mathrm{~m} \Omega \cdot \mathrm{cm})$ p-type (111) $\mathrm{Si}$ wafer. The active region of the device is grown in a single continuous ALD step at $250{ }^{\circ} \mathrm{C}$. A 15 -nm-thick $\mathrm{Al}_{2} \mathrm{O}_{3}$ blocking layer is first deposited followed by a 2-nm-thick $\mathrm{ZnO}$ charge-trapping layer, a 5-nm-thick $\mathrm{Al}_{2} \mathrm{O}_{3}$ tunneling oxide, and, finally, an 11-nmthick $\mathrm{ZnO}$ channel. The top $\mathrm{ZnO}$ layer (channel) is patterned 


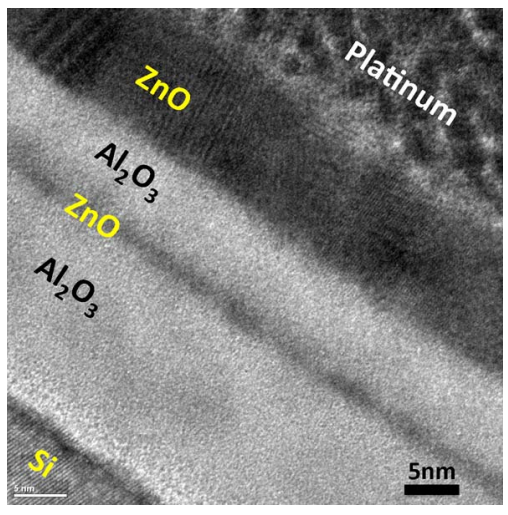

Fig. 2. Cross-sectional TEM image of the active area of the thin-film all-ALD memory cell.

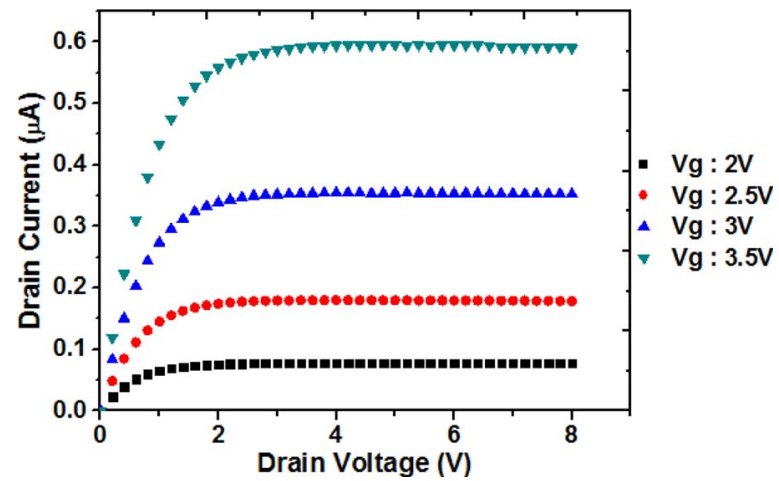

Fig. 3. Measured $I_{\mathrm{drain}}-V_{\mathrm{drain}}$ of the thin-film all-ALD memory cell.

and etched for $2 \mathrm{~s}$ using a 5:95 $\mathrm{H}_{2} \mathrm{SO}_{4}: \mathrm{H}_{2} \mathrm{O}$ solution. A 100-nm-thick Al layer is thermally evaporated and patterned by a liftoff technique to form source and drain contacts. A 360-nmthick electron-beam evaporated $\mathrm{SiO}_{2}$ layer is used for device isolation. A highly doped silicon substrate is used as a backgate electrode. Finally, the samples are annealed in forming gas $\left(\mathrm{H}_{2}: \mathrm{N}_{2} 5: 95\right)$ for $10 \mathrm{~min}$ at $400{ }^{\circ} \mathrm{C}$. Different size channel length $L(2-150 \mu \mathrm{m})$ and width $W(10-100 \mu \mathrm{m})$ devices are fabricated. Cross-sectional transmission electron microscope (TEM) image of a completed thin-film $\mathrm{ZnO}$ memory cell is shown in Fig. 2.

\section{B. Experimental Characterization}

The current-voltage $(I-V)$ characteristics of devices are measured using a Keithley 4200 semiconductor characterization system at room temperature. Fig. 3 plots the transfer characteristics $\left(I_{\text {drain }}-V_{\text {drain }}\right)$ of fabricated devices for different gate biases.

The device behaves as n-channel MOSFETs because the ALD-deposited $\mathrm{ZnO}$ is n-type due to native crystallographic defects such as interstitial zinc and oxygen vacancy that behave as electron donors [17], [18]. The maximum on-to-off ratio of $10^{2}$ (limited by high effective doping concentration of the $\mathrm{ZnO}$ channel due to $250{ }^{\circ} \mathrm{C}$ deposition) is obtained for a device with a gate length and a width of $50 \mu \mathrm{m}$, with a subthreshold slope

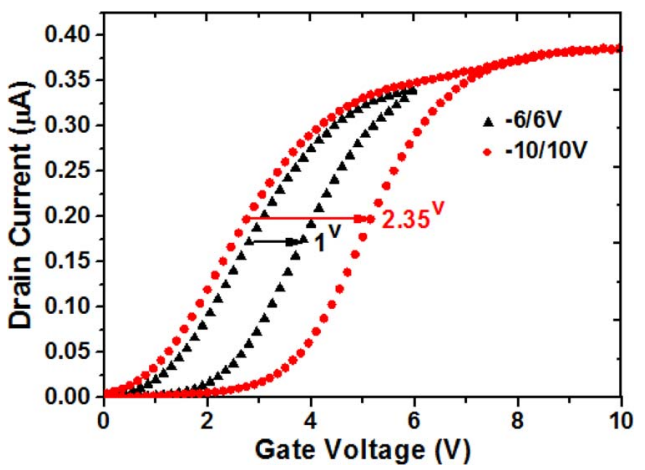

Fig. 4. Measured hysteresis behavior of the $I_{\text {drain }}-V_{\text {gate }}$ characteristics with the gate voltage sweep.

TABLE I

MATERIAl Properties For ZnO AND DiEleCtric LAYERS

\begin{tabular}{llll}
\hline \hline & \multicolumn{1}{c}{$\mathrm{Al}_{2} \mathrm{O}_{3}$} & \multicolumn{1}{c}{$\mathrm{SiO}_{2}$} & \multicolumn{1}{c}{$\mathrm{ZnO}$} \\
\hline Relative permittivity & $9.5(6$ to 9) & 3.9 & 8.75 \\
Energy bandgap & $6.65 \mathrm{eV}$ & $9 \mathrm{eV}$ & $3.37 \mathrm{eV}$ \\
Electron affinity & $2.58 \mathrm{eV}$ & $0.9 \mathrm{eV}$ & $4.5 \mathrm{eV}$ \\
Electron tunnel mass & $0.43 \mathrm{~m}_{0}$ & $0.44 \mathrm{~m}_{0}$ & $0.24 \mathrm{~m}_{0}$ \\
Hole tunnel mass & $0.5 \mathrm{~m}_{0}$ & $1 \mathrm{~m}_{0}$ & $0.59 \mathrm{~m}_{0}$ \\
\hline \hline
\end{tabular}

of $720 \mathrm{mV} / \mathrm{dec}$. The electron mobility $\mu_{e}$ in the $\mathrm{ZnO}$ channel is found to be $23 \mathrm{~cm}^{2} / \mathrm{V} \cdot \mathrm{s}$ using

$$
I_{\text {drain }}=\left(\frac{\mu_{e} \varepsilon_{o} \varepsilon_{r} W}{2 t_{\text {ox }} L}\right)\left(V_{\text {gate }}-V_{t}\right)^{2}
$$

in the saturation region $\left(V_{\text {drain }}>V_{\text {gate }}-V_{t}\right)$, where $\varepsilon_{o}$ and $\varepsilon_{r}$ are the dielectric constants of the vacuum and the $\mathrm{Al}_{2} \mathrm{O}_{3}\left(\varepsilon_{r}=\right.$ 9.5) layer, respectively. $V_{t}$ is the threshold voltage, and $t_{\mathrm{ox}}$ is the thickness of the gate insulator.

In order to experimentally verify the device behaving as a memory, an $I_{\text {drain }}-V_{\text {gate }}$ hysteresis is measured. Fig. 4 shows a typical hysteresis behavior for \pm 6 - and \pm 10 - $\mathrm{V}$ gate voltage sweeps verifying the memory effect. From the figure, there is a $2.35-\mathrm{V}$ hysteresis in the $\pm 10-\mathrm{V}$ gate voltage sweep. Control samples, with no $\mathrm{ZnO}$ trapping layer, show a $<0.6-\mathrm{V}$ hysteresis, which is attributed to unintentional charge trapping in the gate oxide and the oxide-channel interface [19]. The devices exhibit poor retention characteristics potentially due to a continuous $\mathrm{ZnO}$ trapping layer. It should be noted the retention was not optimized in this seminal demonstration.

\section{TCAD Simulations}

In addition to the experiential results, physics-based TCAD simulations using Synopsys TCAD tools is carried out. Material property data used for $\mathrm{ZnO}$ [20] and $\mathrm{Al}_{2} \mathrm{O}_{3}$ [21] are listed in Table I.

The calculated energy band diagram of the structure at zero applied voltage is shown in Fig. 5(a). Both Fowler-Nordheim and direct tunneling models were used throughout the program and erase cycles, allowing electrons to tunnel from the $\mathrm{ZnO}$ channel layer to the trapping layer, and vice versa. The simulation model also includes energy states in the $\mathrm{ZnO}$ layer 

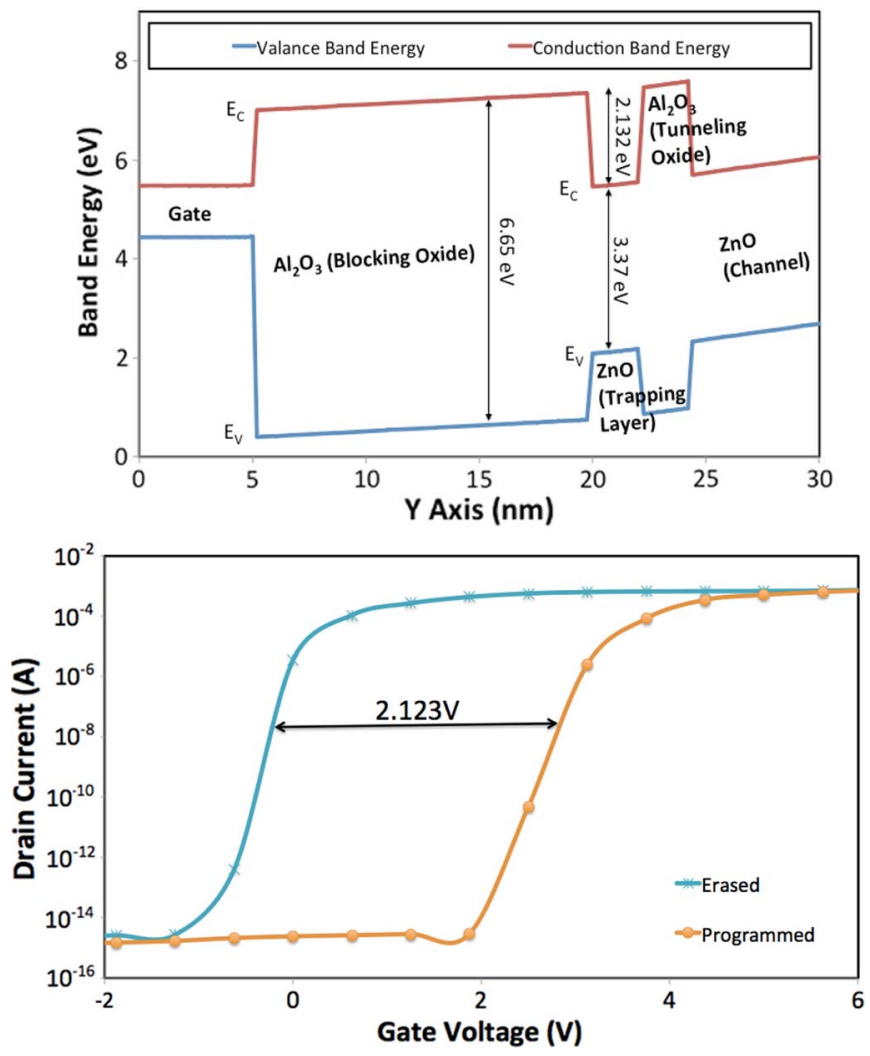

Fig. 5. (a) Calculated energy band diagram of the memory cell. (b) Computed $I_{\text {drain }}-V_{\text {gate }}$ for both program and erase states.

due to crystallographic defects such as interstitial zinc and oxygen vacancy. The $I_{\text {drain }}-V_{\text {gate }}$ characteristics for program and erase states are shown in Fig. 5(b) showing a 2.12-V hysteresis. The $V_{t}$ shift obtained with TCAD agrees well with the $V_{t}$ shift experimentally. This confirms that the electrons that tunnel across the $\mathrm{Al}_{2} \mathrm{O}_{3}$ tunnel oxide are either trapped due to confinement in a quantum well of $2 \mathrm{eV}$ formed by the conduction band offsets between $\mathrm{ZnO}$ and $\mathrm{Al}_{2} \mathrm{O}_{3}$ or in the available energy states within the $\mathrm{ZnO}$ trapping layer.

\section{CONCLUSION}

In summary, a thin-film charge-trapping $\mathrm{ZnO}$ memory cell using a single ALD step has been fabricated for the first time. A hysteresis memory operation is demonstrated with a 2.35-V $V_{t}$ shift measured. TCAD simulations combined with the experimental results provide insight into the chargetrapping mechanisms. In addition, the $\mathrm{ZnO}$ transistor characteristics obtained a rank among the best reported in literature. These results are promising for future low-cost, flexible, and transparent electronic applications.

\section{REFERENCES}

[1] R. L. Hoffman, B. J. Norris, and J. F. Wager, "ZnO-based transparent thinfilm transistors," Appl. Phys. Lett., vol. 82, no. 6, pp. 733-735, Feb. 2003.

[2] R. L. Hoffman, "ZnO-channel thin-film transistors: Channel mobility," $J$. Appl. Phys., vol. 95, no. 10, pp. 5813-5819, May 2004.
[3] E. M. C. Fortunato, P. M. C. Barquinha, A. C. M. B. G. Pimentel, A. M. F. Goncalves, A. J. S. Marques, R. F. P. Martins, and L. M. N. Pereira, "Wide-bandgap high-mobility $\mathrm{ZnO}$ thin-film transistors produced at room temperature," Appl. Phys. Lett., vol. 85, no. 13, pp. 2541-2543, Sep. 2004.

[4] E. M. C. Fortunato, P. M. C. Barquinha, A. C. M. B. G. Pimentel, A. M. F. Goncalves, A. J. S. Marques, L. M. N. Pereira, and R. F. P. Martins, "Fully transparent $\mathrm{ZnO}$ thin-film transistor produced at room temperature," Adv. Mater., vol. 17, no. 5, pp. 590-594, Mar. 2005.

[5] H. Yabuta, M. Sano, K. Abe, T. Aiba, T. Den, H. Kumomi, K. Nomura, T. Kamiya, and H. Hosono, "High-mobility thin-film transistor with amorphous InGaZnO $\sim 4$ channel fabricated by room temperature rf-magnetron sputtering," Appl. Phys. Lett., vol. 89, no. 11, pp. 112123-1-112123-3, Sep. 2006.

[6] S. J. Lim, S. J. Kwon, H. Kim, and J. S. Park, "High performance thin film transistor with low temperature atomic layer deposition nitrogendoped ZnO," Appl. Phys. Lett., vol. 91, no. 18, pp. 183517-1-183517-3, Oct. 2007.

[7] N. Huby, S. Ferrari, E. Guziewicz, M. Godlewski, and V. Osinniy, "Electrical behavior of zinc oxide layers grown by low temperature atomic layer deposition," Appl. Phys. Lett., vol. 92, no. 2, pp. 023502-1-023502-3, Jan. 2008

[8] S. Kwon, S. Bang, S. Lee, W. Jeong, H. Kim, S. C. Gong, H. J. Chang, H.-h. Park, and H. Jeon, "Characteristics of the $\mathrm{ZnO}$ thin film transistor by atomic layer deposition at various temperatures," Semicond. Sci. Technol., vol. 24, no. 3, pp. 035015-1-035015-6, Mar. 2009.

[9] D. Kim, H. Kang, J.-M. Kim, and H. Kim, "The properties of plasmaenhanced atomic layer deposition (ALD) $\mathrm{ZnO}$ thin films and comparison with thermal ALD," Appl. Surf. Sci., vol. 257, no. 8, pp. 3776-3779, Feb. 2011.

[10] K. Nomura, H. Ohta, A. Takagi, T. Kamiya, M. Hirano, and H. Hosono, "Room-temperature fabrication of transparent flexible thin-film transistors using amorphous oxide semiconductors," Nature, vol. 432, no. 7016, pp. 488-492, Nov. 2004.

[11] J. Siddiqui, E. Cagin, D. Chen, and J. D. Phillips, "ZnO thin-film transistors with polycrystalline(Ba,Sr)TiO3 gate insulators," Appl. Phys. Lett., vol. 88, no. 21, pp. 212903-1-212903-3, May 2006.

[12] D. Gupta, M. Anand, S. W. Ryu, Y. K. Choi, and S. Yoo, "Nonvolatile memory based on sol-gel $\mathrm{ZnO}$ thin-film transistors with Ag nanoparticles embedded in the $\mathrm{ZnO} /$ gate insulator interface," Appl. Phys. Lett., vol. 93, no. 22, pp. 224106-1-224106-3, Dec. 2008.

[13] H. Yin, S. Kim, C. J. Kim, I. Song, J. Park, S. Kim, and Y. Park, "Fully transparent nonvolatile memory employing amorphous oxides as charge trap and transistor's channel layer," Appl. Phys. Lett., vol. 93, no. 17, pp. 172109-1-172109-3, Oct. 2008.

[14] S. Kang, Y. Kim, H. S. Seo, S. W. Son, E. A. Yoon, S. Joo, and C. W. Ahn, "High-performance and room-temperature-processed nanofloating gate memory devices based on top-gate transparent thin-film transistors," Appl. Phys. Lett., vol. 98, no. 21, pp. 212102-1-212102-3, May 2011.

[15] E. Kim, Y. Kim, D. H. Kim, K. Lee, G. N. Parsons, and K. Park, " $\mathrm{SiN}_{x}$ charge-trap nonvolatile memory based on $\mathrm{ZnO}$ thin-film transistors," Appl. Phys. Lett., vol. 99, no. 11, pp. 112115-1-112115-3, Sep. 2011.

[16] C. G. Van de Walle, "Hydrogen as a cause of doping in zinc oxide," Phys. Rev. Lett., vol. 85, no. 5, pp. 1012-1015, Jul. 2000.

[17] S. H. K. Park, C. S. Hwang, H. S. Kwack, J. H. Lee, and H. Y. Chu, "Characteristics of $\mathrm{ZnO}$ thin films by means of plasma-enhanced atomic layer deposition," Electrochem. Soild-State Lett., vol. 9, no. 10, pp. G299G301, Jul. 2006.

[18] Y. T. Shih, M. K. Wu, M. J. Chen, Y. C. Cheng, J. R. Yang, and M. Shiojiri, "ZnO-based heterojunction light-emitting diodes on $\mathrm{p}-\mathrm{SiC}(4 \mathrm{H})$ grown by atomic layer deposition," Appl. Phys. B, Photophys. Laser Chem., vol. 98, no. 4, pp. 767-772, Mar. 2010.

[19] S. Chang, Y. W. Song, S. Lee, S. Y. Lee, and B. K. Ju, "Efficient suppression of charge trapping in ZnO-based transparent thin film transistors with novel A12O3/HfO2/A12O3 structure," Appl. Phys. Lett., vol. 92, no. 19, pp. 192104-1-192104-3, May 2008.

[20] M. L. Huang, Y. C. Chang, C. H. Chang, T. D. Lin, J. Kwo, T. B. Wu, and M. Hong, "Energy-band parameters of atomic-layerdeposition-A12O3/InGaAs hetero-structures," Appl. Phys. Lett., vol. 89, no. 1, pp. 012903-1-012903-3, Jul. 2006.

[21] J. Bu and M. H. White, "Design considerations in scaled SONOS nonvolatile memory devices," Solid-State Electron., vol. 45, no. 1, pp. 113120, Jan. 2001. 